Personalidade Acadêmica Homenageada:

Florisbal de Souza Del'Olmo (Professor Convidado - UNICURITIBA)

\title{
DUE DILIGENCE: O CRITÉRIO ÉTICO DA MAXIMIZAÇÃO DE RIQUEZAS DE RICHARD POSNER COLOCADO EM APLICAÇÃO EM OPERAÇÕES DE FUSÕES E AQUISIÇÕES
}

\section{DUE DILIGENCE: RICHARD POSNER'S WEALTH MAXIMIZATION ETHICAL STANDARD APPLIED TO MERGER AND AQUISITION TRANSACTIONS}

SANDRO MANSUR GIBRAN

Professor Permanente do Programa de Mestrado em Direito Empresarial e Cidadania - UNICURITIBA

\section{GABRIEL JACOBS DE OLIVEIRA}

Mestrando em Direito Empresarial e Cidadania pela Faculdade de Direito do Centro Universitário Curitiba - UNICURITIBA. E-mail: gabrieljoliveira@outlook.com.

\section{RESUMO}

Este estudo procura estabelecer uma relação entre o critério moral da maximização de riquezas, de Richard Posner, com a realização de Pré-contratos de compra e venda de empresas que antecedem a consolidação de uma operação de fusão e aquisição de sociedade empresárias, em especial ao que se refere à realização de due diligences entre a a celebração de ditas avenças com a finalização do negócio jurídico. Com isto, a presente pesquisa está pautada na resposta para o seguinte questionamento: "De que forma é possível reconhecer a aplicação do critério da maximização de riquezas em operações de fusão e aquisição de sociedade empresárias?", de modo a justificar juseconomicamente a celebração de avenças prévias à consolidação desta modalidade de contratação no âmbito do direito 


\section{Personalidade Acadêmica Homenageada:}

Florisbal de Souza Del'OImo (Professor Convidado - UNICURITIBA)

empresarial. O presente estudo é pautado no fundamento epistêmico do racionalismo, que ganha forma a partir do emprego do método dedutivo de análise, atingido através da leitura de livros, artigos científicos e da pesquisa documental, cumprindo esta última forma de pesquisa com a finalidade de aproximar o estudo com a realidade, muitas vezes abandonada em prol da pesquisa meramente teórica. O presente artigo foi construído a partir da seguinte estrutura: 1) Introdução; 2) A maximização de riquezas como critério ético; 3) Acordos preliminares em operações de fusões e aquisições de sociedade empresárias; 4) A prática da due diligence; 5) A aplicação do critério ético da maximização de riquezas à prática da du diligence; 6) Considerações finais. Ao final da investigação foi possível estabelecer que a critério ético da maximização de riquezas pode ser verificado a partir da análise das características e finalidades da prática da due diligence, na medida em que esta prática viabiliza tomar conhecimento sobre o real valor econômico de determinado negócio, de modo a impedir a realização de uma operação financeira em que uma das partes envolvidas acabe recebendo ou pagando valores que não lhe maximize a utilidade da fusão ou aquisição, evitando-se, assim, uma situação de ineficiência econômica, segundo o critério da maximização de riquezas de Posner.

PALAVRAS-CHAVE: Maximização de Riquezas; Eficiência; Posner; Análise Econômica do Direito.

\section{ABSTRACT}

This study seeks to establish a relationship between the moral standard of wealth maximizing, by Richard Posner and the execution of preliminar agreements on mergers and aquistion transactions as well as the performance of due diligences that takes place between the pre-contract and the final agreement. Thus, the present research aims to answer the following question: "In what way is it possible to recognize the application of the wealth maximization ethical standard in operations of merger and acquisition of companies?", justifying legally and economically the 


\section{Personalidade Acadêmica Homenageada:}

Florisbal de Souza Del'Olmo (Professor Convidado - UNICURITIBA)

celebration of agreements prior to the final agreements on this kind of contracts. The present study is based on the epistemic foundation of rationalism, based on deductive method of analysis, achieved through books, scientific articles and documental research. The present article was constructed with the following structure: 1) Introduction; 2) The wealth maximization as an ethical standard; 3) Preliminary agreements on mergers and acquisitions transactions; 4) The due diligence process; 5) The link between wealth maximization ethical standard and due diligence; 6) Final considerations. At the end of the investigation it was possible to establish that the ethical standard of wealth maximization can be verified from the analysis of the characteristics and purposes of the due diligence practice, insofar as this practice makes it possible to know about the real economic value of a given business, in order to prevent the execution of a financial transaction in which one of the parties involved ends up receiving or paying values that do not maximize the utility of the operation, avoiding a situation of economic inefficiency, according to the ethical standard of maximization proposed by Posner.

KEYWORDS: Wealth Maximzation; Efficiency; Posner; Law and Economics.

\section{INTRODUÇÃO}

Muito se escreve sobre a realização de due diligence em processos de contratação, seja na aquisição de bens e serviços, para que, entre outras coisas, seja possível ter uma visão macro de quem se está figurando na outra parte da relação contratual, seja pela necessidade de saber se a parceria comercial em potencial poderá representar riscos financeiros, éticos ou legais para a empresa.

São igualmente muito encontrados estudos que fazem uma análise sobre a importância de se realizar investigações prévias à celebração de contratos com clientes, para que se assegure que a venda de produtos ou de serviços não estejam 


\section{Personalidade Acadêmica Homenageada:}

Florisbal de Souza Del'Olmo (Professor Convidado - UNICURITIBA)

correlacionados à situações ilegais ou antiéticas, que poderiam prejudicar a imagem da empresa perante o mercado.

Outras pesquisas apresentam correlação maior com a presente, porque objetivam explorar a realização de due diligences em processos de fusão e aquisição de empresas, sem, necessariamente justificar teoricamente possíveis fundamentos juseconômicos do porque a prática em questão é realizada quase que na totalidade de transações desta natureza.

É justamente sob a perspectiva de se justificar juridicamente e economicamente a prática, que se redigiu o presente artigo.

Richard Posner passou grande parte de sua vida estudando o direito a partir da economia, o que lhe permitiu construir uma teoria ética e moral pautada na geração de valor para que se gere mais valor.

Sua construção teórica - muito criticada, é verdade - buscou justificar com fundamentos utilitaristas o princípio do direito: a justiça.

Com isto, desenvolveu o que ficou como o fundamento moral e ético da maximização de riquezas, sendo este eleito, nesta oportunidade, como pressuposto analítico da prática da due diligence em transações comerciais envolvendo fusão e aquisição de sociedades mercantis.

Pertinente, pois, a presente investigação da prática comercial da investigação prévia durante a fase preliminar de transações de fusão e aquisição, por esta ser convidativa para uma análise teórica de uma situação muito prática, geralmente analisada estritamente sob o enfoque puramente pragmático.

Ultrapassada as noções introdutórias acerca deste estudo, convém destacar que seu objetivo central consiste em responder "De que forma é possível reconhecer a aplicação do critério da maximização de riquezas em operações de fusão e aquisição de sociedade empresárias?", bem como instigar a investigação de fatos jurídicos do relevantes ao direito empresarial a partir de uma perspectiva econômica.

Para fins de se responder ao questionamento norteador da investigação, foi utilizado o método dedutivo, com fundamento epistemológico racionalista, construído a partir da leitura de de livros, artigos científicos e da pesquisa documental 


\section{Personalidade Acadêmica Homenageada:}

Florisbal de Souza Del'OImo (Professor Convidado - UNICURITIBA)

relacionados ao tema, os quais serviram como arcabouço para se promover uma análise teórica sem, no entanto, abandonar o pragmatismo inerente à questão explorada.

Estruturou-se o presente artigo em seis tópicos, sendo o primeiro correspondente a uma breve introdução, no qual será possível tomar conhecimento das justificativas que levaram à investigação da temática, bem como identificar seu marco teórico e suas questões estruturais e metodológicas.

$\mathrm{Na}$ sequência abordou-se exclusivamente a questão da maximização de riquezas e seus fundamentos, sob a ótica de Richard Posner.

Ato contínuo, o estudo em questão se ocupou de percorrer questões inerentes aos contratos preliminares à concretização de transações de fusão e aquisição de empresas, para então investigar a prática da due diligence.

Já nos últimos dois últimos tópicos, respectivamente, se estabeleceu uma relação entre o critério moral e ético da maximização de riquezas e a prática da due dilgence, permitindo que se chegasse às considerações finais retomando a questionamento norteador da pesquisa e respondendo-o.

\section{A MAXIMIZAÇÃO DE RIQUEZAS COMO CRITÉRIO ÉTICO}

Em "A Economia da Justiça", Richard Posner propõe uma investigação sobre diversos conceitos normalmente analisados exclusivamente a partir de fundamentos filosóficos e jurídicos, sob a perspectiva econométrica.

Durante sua análise, Posner percorre diversos institutos como "o significado a justiça, a origem do Estado, o direito primitivo, a retribuição, o direito à privacidade, a difamação, a discriminação racial e a ação afirmativa." e assim o faz estabelecendo como pressuposto analítico o princípio econômico de que cada indivíduo age racionalmente de modo a maximizar sua satisfação. (POSNER, 2010, p. 3). 


\section{Personalidade Acadêmica Homenageada: \\ Florisbal de Souza Del'Olmo (Professor Convidado - UNICURITIBA)}

Explica o autor que todos os demais princípios econômico são consequências da máxima anteriormente apontada, como, por exemplo:

[...] o princípio de que uma mudança no preço de um bem de consumo afetará a qualidade disponível desse bem por fomentar o surgimento de bens de consumo substitutos, ou de que os recursos são direcionados para onde se mostrarem mais lucrativos, ou o princípio de que um indivíduo distribuirá seu orçamento entre os produtos e serviços disponíveis de maneira tal que o dólar marginal (último dólar) gasto em cada produto ou serviço the proporcione a mesma satisfação; caso isto não ocorra, ele poderá aumentar sua utilidade ou seu bem-estar total por meio de uma realocação de seus recursos financeiros. (POSNER, 2010, p. 3-4).

Posner acredita que é implausível que os comportamentos humanos sejam segregados em pequenos compartimentos ou seja, que as pessoas ajam de maneira racional ao fazer compras, ao passo que ao decidir sobre outra situações que não sejam diretamente mercadológicas (escolha da faculdade, por exemplo), agiriam de forma não racional. (POSNER, 2010, p. 4).

A consequência dos estudos realizados por Posner permitiram-Ihe formar uma "teoria da justiça" - embora não a nomeasse desta forma - pautada no critério ético da maximização de riquezas vez que esta é "positivamente vinculada, ainda que de forma imperfeita, à utilidade, mas a busca da riqueza, fundada que está no modelo de transação voluntária de mercado, envolve um respeito às escolhas individuais maior do que aquele que se vê no utilitarismo" (POSNER, 2010, p. 79), ou seja, para o autor, para que se possa bem fazer análises econômicas no campo jurídico, considerar-e-á o critério ético da maximização de riquezas como pressuposto de eficiência dos fatos juridicamente relevantes.

A escolha da maximização de riquezas como critério ético justifica-se uma vez que:

[...] ela fornece bases mais sólidas para uma teoria da justiça distributiva e corretiva. Já se observou que a fonte dos direitos negociados em uma economia de mercado é, ela própria, necessariamente externa ao princípio da maximização de riqueza. Na verdade, o princípio preestabelece a criação de um sistema de direitos pessoais e de propriedade que teoricamente se aplicaria a todas as coisas escassas - não só à propriedade pessoal e imobiliária, mas ao corpo humano e até as ideais (POSNER, 2010, p. 83). 


\section{Personalidade Acadêmica Homenageada: \\ Florisbal de Souza Del'Olmo (Professor Convidado - UNICURITIBA)}

Neste sentido, o ordenamento jurídico estaria adstrito à proteção de três institutos principais. São eles: o direito á propriedade, o direito obrigacional e contratual e a responsabilização civil ${ }^{1}$. Todas estas forças motrizes do sistema estariam voltadas à geração de valor e, portanto, o critério a ser utilizado para guiar a noção de justiça não poderia estar completamente dissociado da concepção da maximização de riquezas (SALAMA, 2008, p. 3), o que justificaria a eleição da maximização de riqueza como critério ético a ser seguido.

Com isto, possível é compreender a maximização de riquezas como corolária da eficiência econômica, com bases filosóficas no utilitarismo, ou seja, trata-se de um situação eficiente na qual as trocas realizadas entre as partes tenham gerado as maiores repercussões econômicas possíveis na situação, com o maior número de situações "ganha-ganha" possíveis.

Ainda neste sentido, parece plausível imaginar que uma operação de crédito realizada de forma idônea, através de um cheque no valor de mil reais, que endossado por diversas vezes, representando, pois, operações financeiras muito superiores ao seu valor nominal possa ser considerado um caso de eficiência econômica ou, como Posner preferiu nomear, uma situação em que se diversas pessoas tenham realizado suas transações financeiras a partir de um mesmo título de crédito.

Não se confunde a maximização de riquezas com operações econômicas que não exista repercussão econômica positiva para ambas as partes, como, por exemplo, na hipótese de furto, conforme analisado por Posner em seu livro:

Comparemos novamente um homem que está disposto a pagar $\$ 10.000$ por um colar e o que não tem dinheiro, mas está disposto a incorrer em uma desutilidade não pecuniária equivalente à de desistir de tal quantia. A posição do primeiro homem é moralmente superior, pois ele busca aumentar seu bem-estar beneficiando outra pessoa, a saber, o dono do colar. Além disso, ao que tudo indica, o comprador acumulou seus $\$ 10.000$ por meio de atividade produtiva, isto é, de uma atividade que beneficiou

\footnotetext{
${ }^{1} \mathrm{~A}$ análise do autor é pautada no direito estadunidense.
} 


\title{
Personalidade Acadêmica Homenageada:
}

Florisbal de Souza Del'Olmo (Professor Convidado - UNICURITIBA)

\begin{abstract}
outras pessoas além dele, sejam estas seus empregadores, clientes [...] O comprador, em nosso exemplo, confere um benefício líquido ao dono do colar (que, do contrário, não aceitaria \$10.000: mas, em cada fase da acumulação dessa quantia por meio de atividade produtiva, confeririam-se benefícios líquidos a outras pessoas além do produtor. O ladrão, ao contrário, não beneficia o dono do colar nem qualquer outra pessoa. (POSNER, 2010, p. 79-80).
\end{abstract}

Assim, a maximização de riquezas para Posner pode ser traduzida como situações de interação econômica geradores de valor em que haja o benefício de diversas pessoas, seja pela liquidez financeira da transação, seja pelo número de pessoas economicamente beneficiadas ou pelo prazer da aquisição de determinado objeto.

Estas situações econômicas acabam, segundo Posner, por desencadear o bem-estar social e, portanto, correspondem ao que se pode denominar de critério ético da maximização de riquezas, podendo este ser compreendido como um critério de justiça.

O que se pretende com este estudo é, portanto, estabelecer uma ligação entre a realização de due diligences em processos de fusão e aquisição de sociedades empresárias, posto que a finalidade de suas realizações parece estar relacionada com a necessidade de se calcular a realidade econômica da transação, evitando-se, assim, a realização de uma transação econômica que não esteja norteada pelo critério ético da maximização de riquezas.

\section{ACORDOS PRELIMINARES EM OPERAÇÕES DE FUSÕES E AQUISIÇÕES DE SOCIEDADES EMPRESÁRIAS}

A celebração de acordos preliminares é muito explorada no direito privado como um todo, desde a aquisição de um imóvel até a realização de operações multimilionárias envolvendo a aquisição ou fusão de sociedades empresárias. 


\section{Personalidade Acadêmica Homenageada:}

Florisbal de Souza Del'Olmo (Professor Convidado - UNICURITIBA)

Tem-se por acordo preliminar o contrato que tem como objeto a celebração de outro no futuro, ou seja, há um comprometimento instrumentalizado de que se celebrará um contrato principal. (TEIXEIRA, 2015, p. 29-31).

Conforme antecipado, um dos exemplos mais palpáveis ao abordar a temática é o da celebração da promessa de compra (contrato preliminar) e venda de um imóvel residencial, pelo qual o promitente comprador e o promitente vendedor acordam que assinarão em algum tempo a escritura pública de compra e venda (contrato principal).

Segundo TEIXEIRA (2015, p. 71), a promessa de compra e venda imobiliária torna viável que o promitente vendedor exija o valor da pactuado entre as partes, ao passo que confere ao comprador a possibilidade de demandar a transferência do bem por meio do instrumento definitivo.

Muito embora o exemplo menos complexo seja o supramencionado, não se pode ignorar outras modalidades um pouco menos usuais de contratos preliminares, tais como o pré-contrato de shopping center, o pré-contrato de constituição de sociedade empresária, o pré-contrato de leasing, o pré-contrato de franquia, bem como o acordo preliminar típico das operações de fusão e aquisição de sociedades empresárias, por diversas vezes referenciado como memorando de entendimentos.

Não se pode ignorar o fato de que apesar da classificação doutrinária ser de fácil compreensão, muitas vezes as negociações e o conteúdo destes documentos se confundem com protocolos de intenções que não tenham por objeto a obrigação de celebração de um contrato principal.

Meros protocolos de intenções possuem a função de viabilizar um melhor entendimento entre as partes sobre as características e peculiaridades de possíveis futuros negócios e costumam conter cláusulas de não divulgação das informações compartilhadas e outras peculiaridades que não se confundem com o objeto de um contrato definitivo.

Acredita-se que uma distinção possível entre os pré-contratos e os protocolos de intenção esteja relacionada com o conteúdo semelhante ao do negócio principal, ou seja, em uma situação jurídica que verse sobre compra e 


\section{Personalidade Acadêmica Homenageada: \\ Florisbal de Souza Del'Olmo (Professor Convidado - UNICURITIBA)}

venda, é possível que vislumbre um pré-contrato se no instrumento sob análise contiverem informações de determinação da coisa a ser vendida e da forma de precipitação ou remuneração pela coisa, que, por consequência, não elementos essenciais ao contrato principal de compra e venda. (TEIXEIRA, 2015, p. 46).

Esta troca preliminar de informações pode ser compreendida como:

[...] marcada pela troca preliminar de informações entre as partes, discussões sobre suas intenções e definição dos próximos passos da transação. Acima de tudo, o desenrolar dessa etapa determinará a continuação, ou não, do processo de formação e celebração do Contrato de Aquisição. Prevalece o princípio da liberdade contratual, pois qualquer das partes pode encerrar as tratativas sem que Ihes seja imposta qualquer sanção ou dever de indenizar. (LUIZE, 2016, p. 156).

Em sentido oposto:

[...] o objeto do contrato preliminar não é a empresa-alvo, mas a própria celebração do negócio relativo à alienação da empresa- -alvo. Por ele, as partes assumem a obrigação de celebrar o contrato final e, para tanto, é necessário que contenha todos seus requisitos essenciais, exceto quanto à forma (LUIZE, 2016, p. 158).

O uso de acordos preliminares é comumente empregado em situações em que as partes negociem fusões ou aquisições de sociedades empresárias, sendo a primeira correspondente a "uma operação de concentração de empresas, na qual duas ou mais sociedades se unem, resultado dessa união uma nova sociedade" (BERTOLDI; RIBEIRO, 2016, p. 364) e a segunda podendo ser uma situação de incorporação, venda de controle acionário ou simples compra de estabelecimento empresarial.

Nestas modalidades de contratação, pode-se segregar o momento em que as partes se aproximam para obter informações sobre a contraparte com a finalidade de verificar se um negócio entre si poderá ser proveitoso a ambas, com o momento em que as partes passam a discutir questões mais técnicas (jurídicas, financeiras e estratégicas), nos termos que seguem: 


\title{
Personalidade Acadêmica Homenageada: \\ Florisbal de Souza Del'OImo (Professor Convidado - UNICURITIBA)
}

\begin{abstract}
Processos de F\&A geralmente se iniciam pelo contato da administração das sociedades envolvidas e pela troca de informações entre seus sócios ou acionistas, com o propósito de verificar se o negócio será proveitoso e criará sinergias e oportunidades comerciais às partes. Trata-se de fase de prénegociação, popularmente conhecido como "namoro", na qual as tratativas ainda são informais e são trocadas impressões preliminares sobre 0 negócio, de forma a confirmar se os gastos com assessores e o tempo e a exposição sacrificados na negociação farão sentido.Uma vez que o interesse pela transação é confirmado, inicia-se a fase de due diligence (normalmente, jurídica, financeira e estratégica) da sociedade-alvo. (LUIZE, 2016, p. 154).
\end{abstract}

Como visto, uma vez consolidado o protocolo de intenções e as partes decidam que o negócio é proveitoso, estas passarão ao acordo preliminar, antecessor à formalização do negócio definitivo, cuja finalidade, na maioria dos casos é a de se consolidar, por meio de uma due diligence - ou auditoria - questões relacionadas à precificação e a estratégia, a conclusão do negócio em suma, as partes movem para a fase em que se estabelecem critérios de preço e definem objetivamente o objeto da fusão e (ou) aquisição.

\section{A PRATICA DA DUE DILIGENCE}

Conforme percorrido no tópico anterior, uma vez que as partes decidam avançar com as negociações, existe a necessidade de se desenhar uma estratégia para a conclusão do negócio, bem como bem delimitar o objeto (a extensão da operação) e o preço.

Para tanto, é necessário que profissionais muito capacitados de diversas áreas do conhecimento sejam introduzidos na operação.

A equipe multidisciplinar constantemente acionada costuma contar com advogados, contadores, economistas e administradores que estarão encarregados de fazer uma diligência prévia à conclusão do negócio.

Esta diligência prévia ou, em inglês, due diligence é de extrema importância para que as partes saibam exatamente o quanto deverão desembolsar e (ou) receber pela operação, bem como possam identificar a saúde financeira da outra 


\section{Personalidade Acadêmica Homenageada: \\ Florisbal de Souza Del'OImo (Professor Convidado - UNICURITIBA)}

parte $^{2}$ e (ou) possíveis riscos existentes na esfera trabalhista, tributária, regulatória e em relações governamentais ${ }^{3}$.

A due dligence é normalmente explicada em estudos a partir de dois conceitos típicos das ciências econômicas, quais sejam, a assimetria informacional e os custos de transação.

A questão da assimetria de informações deve ser tratada a partir do pressuposto de que as partes não possuem de forma completa e livre todas as informações necessárias para que se prossiga com a negociação e que estas informações possuem valor econômico gigantesco. Por isto, existe a disponibilização de parte destas informações em fase de protocolo de intenções e a confirmações e maior exploração de outras informações já em fase de acordo preliminares, como uma maneira de se equilibrar a balança informacional. (RAMOS, 2012, p. 40).

Também devem ser consideradas que a tomada de conhecimento das informações possibilita às partes envolvidas o maior conhecimento sobre a operação de fusão e aquisição, minorando custos de transação ${ }^{4}$ que surgiriam com 0 prosseguimento e conclusão dos negócios sem a avaliação da negociação sob os diversos prismas explorados nesta fase de acordo preliminar.

A função destes estudos já em fase de contratação preliminar é justamente o de se colocar a prova as informações apresentadas na fase de protocolo de intenções, como uma forma de se mitigar exposições financeiras, conforme aprofundado no trecho que segue:

Ainda neste ponto, é importante notar que a due diligence não é uma simples liberalidade das partes ou mera burocracia. Ela nasce e se desenvolve com fundamento na redução de riscos e prejuízos futuros

\footnotetext{
${ }^{2}$ São estudados dados como o EBITDA (Earinings Before Interest, Taxes, Depreciation and Amortization), cuja finalidade é a de se avaliar a capacidade da sociedade gerar lucro, bem como o fluxo de caixa da empresa, dado importante para fins de demonstrar a liquidez da empresa.

${ }^{3}$ Verificam-se questões relacionadas ao envolvimento da sociedade em situações de corrupção, suborno e a forma de condução de negócios - se ética ou não.

${ }^{4}$ Jargão utilizado na economia e na análise econômica do direito para referenciar os custos inerentes às negociações entre as partes. Quando se reduz os custos envolvidos em determinada negociação e ambas as partes passam a se encontrar uma situação de "win-win" é possível determinar que se encontrou a eficiência.
} 


\section{Personalidade Acadêmica Homenageada:}

Florisbal de Souza Del'Olmo (Professor Convidado - UNICURITIBA)

oriundos da tal assimetria de informações, buscando-se o lucro de forma alicerçada e segura. (RAMOS, 2012, p. 45)

É no momento da due diligence que se confirmam as informações prestadas nos protocolos de intenção e se prosseguirá com a celebração do contrato principal.

Com isto, parece possível compreender a função da due diligence como uma forma de se confrontar e obter outras informações sobre a negociação, fazendo com que as partes possam chegar a um valor justo para as partes e que a transação se de de forma eficiente, garantindo a ambas as partes, de certa forma, a maximização de suas riquezas.

\section{A APLICAÇÃO DO CRITÉRIO ÉTICO DA MAXIMIZAÇÃO DE RIQUEZAS À PRÁTICA DA DUE DILIGENCE}

Conforme visto anteriormente, o critério ético da maximização de riquezas é exemplificado por Posner a partir da situação envolvendo um colar cujo valor seria de 10 mil dólares.

A pessoa que detém o referido colar possui o benefício de simplesmente ter o colar, haja vista que existe um valor inerente ao objeto, o qual somente será trocado mediante a geração de valor maior ao que o seu proprietário acredita valer, ou seja, em contrapartida à transmissão de propriedade do colar haverá uma compensação - não necessariamente financeira - que desencadeará um benefício econômico ao seu até então proprietário.

Em contrapartida, outra pessoa estará disposta a pagar o valor de 10 mil reais pelo colar, entendendo, assim, que ao comprar do colar, mesmo havendo a redução de valor pecuniário na composição de seu patrimônio, este será compensado pela propriedade sob o colar, seja esta para revenda por preço superior ou por qualquer outra vantagem que não esteja necessariamente relacionada com a imediata geração de renda. 


\section{Personalidade Acadêmica Homenageada:}

Florisbal de Souza Del'Olmo (Professor Convidado - UNICURITIBA)

Esta situação, segundo Posner, é deveras diferente de uma relação em que o proprietário do colar tenha sofrido o furto do objeto, haja vista que a primeira hipótese se encaixara perfeitamente no critério ético da justiça e do juseconômico da eficiência, ou seja, existe a geração de valor para ambas as partes envolvidas na transação.

O caso do furto, no entanto, é incapaz de gerar valor para ambos os agentes da situação, o que, por consequência, acarretaria na não geração de valor para ambas as partes, na ineficiência juseconômica do situação e, assim, em injusta.

Pode-se imaginar que a teoria sobre maximização de riquezas de Posner encontre certa resistência se imaginarmos o valor social que determinado furto possa vir a gerar, como em uma situação em que o colar tenha sido posteriormente vendido e o valor pecuniário dividido em outras 10 pessoas que usarão este dinheiro para fazerem outras transações comerciais, as quais gerariam maior valor para muitas outras pessoas, não estando o proveito econômico restrito a apenas um comprador e um vendedor, como no primeiro caso.

Parece, no entanto, que Posner acredita que uma situação na qual existe o prejuízo de uma parte, a eficiência global do caso estaria corrompida, provavelmente porque nada repararia o prejuízo correspondente à propriedade do colar em primeiro lugar.

Apesar disto, se for levado em consideração que o critério ético da maximização de riquezas é apenas atingido quando existe geração de valor para ambos; um equilíbrio econômico entre a prestação e a contraprestação, passa a se tornar possível imaginar que, segundo esta lógico, a prática da due diligence é, em verdade, uma maneira de se garantir que haja a justa geração de valor para ambas as partes e que, assim, a transação de fusão e aquisição de sociedade empresárias se de maneira justa e eficiente.

Isto porque, conforme visto nos tópicos anteriores, a realização da due diligence serve como:

[...] um procedimento que identifica os aspectos econômicos, financeiros, e físicos, entre os quais fazem parte as variáveis ambientais que estejam 


\title{
Personalidade Acadêmica Homenageada: \\ Florisbal de Souza Del'OImo (Professor Convidado - UNICURITIBA)
}

\begin{abstract}
afetando, ou poderão vir a afetar, a situação patrimonial de uma companhia. Para Perez e Famá (2004), em processos de fusões e aquisições, procedimentos de due diligence são efetuados como forma de obtenção de informações que possam afetar o futuro da empresa e consequentemente seu fluxo de caixa e seu valor econômico [...] Alguns objetivos da utilização de due diligence pela parte compradora são: identificar e gerenciar riscos de diversas áreas (ambiental, TI, fiscal, trabalhista, financeiro), avaliar compatibilidade de filosofia, confirmar a rentabilidade da operação (EBITDA), base de cálculo do goodwill, quantificar o patrimônio contábil, conhecer o funcionamento da empresa, identificar pontos fortes e fracos, entender a gestão administrativa e contábil, conhecer o ambiente de controles internos, avaliar o risco, fornecer dados para minuta do contrato de fusão e aquisição, fornecer dados para planos de pós-aquisição e fornecer dados para planos financeiros de aquisição. (RAUPP; WARKEN, 2009, p. 37).
\end{abstract}

Neste sentido, se abandonadas as limitações da teoria construída por Posner, principalmente aquelas relacionadas com a visão meramente econométrica de seu pensamento e da insuficiência da maximização de riquezas poder ser considerada um critério ético e de justiça a ser perseguido pela sociedade como um todo, parece ser, ao menos possível colocar suas teoria à prova na medida em que esta é testada a partir da ótica das transações de fusões e aquisições de empresas, em especial no que se refere à prática da due diligence.

Isto se dá justamente porque Posner acredita que a eficiência e a justiça são pautadas na geração de valor para ambas as partes que se relacionam, ou seja, em uma situação de ganha-ganha.

Em fusões e aquisições de empresas, a partir da realização da due diligence e da análise de seus resultados, torna-se possível estabelecer os riscos inerentes ao negócio, as perspectivas de negócio, a realidade patrimonial da empresa (fluxo de caixa, ativos circulantes e imobilizados, ebitda) e, assim, sendo possível de se estabelecer um preço condizente à operação, evitando-se portanto - pelo menos em tese - que nenhuma das partes seja prejudicada na hora de determinar o preço a ser pago ou recebido.

Uma vez que a transação tenha sido completada desta forma, poderá se considerar que ela foi capaz de gerar valor e de maximizar riquezas, sendo, assim, eficiente e justa, segundo a teoria de Richard Posner. 


\section{CONCLUSÃO}

No decorrer deste estudo, buscou-se apresentar a teoria da maximização de riquezas de Richard Posner, que, para o referido autor, parece estar intimamente ligada com a noção de justiça.

A maximização de riquezas como critério ético foi escolhida como marco teórico para que se analisasse a prática de due diligence em operações de fusão e aquisição de empresas, sendo que esta geralmente decorrer de acordos preliminares necessários à concretização do negócio final.

Acredita-se que ao estruturar o estudo desta maneira, foi possível fornecer subsídios para que se respondesse ao questionamento formulado no início do desenvolvimento desta investigação, ou seja, responder "De que forma é possível reconhecer a aplicação do critério da maximização de riquezas em operações de fusão e aquisição de sociedade empresárias?".

Como visto anteriormente, Richard Posner não admitia que uma transação econômica eficiente pudesse ser realizada sem que esta gerasse riquezas para todas as partes envolvidas, exemplificando esta situação a partir do exemplo do colar furtado, que só garante benefícios econômicos a uma das partes, não gerando riquezas para ambas.

Com isto, submeteu-se a realização de due diligence à teoria da maximização de riquezas e percebeu-se que tal situação possibilita ao comprador saber exatamente o que está comprando e ao vendedor saber exatamente quem está comprando e o que está vendendo, permitindo às partes terem acesso às informações de forma mais abrangente, conclui-se que tal situação permite às partes chegarem ao preço correto da transação. 
Personalidade Acadêmica Homenageada:

Florisbal de Souza Del'OImo (Professor Convidado - UNICURITIBA)

Uma vez que as partes conseguiram chegar ao preço correto da operação, parece possível estabelecer que a transação será executada de forma a gerar o máximo de riquezas que poderia, tornando-se, então, eficiente e juta.

Com isto, o presente estudo permite que se considere que a realização de due diligence em operações de fusão e aquisição de empresas seja considerada um meio pra que comprove o critério ético da maximização de riquezas, o que responde ao questionamento norteador da investigação.

\section{REFERÊNCIAS}

BERTOLDI, Marcelo M.; RIBEIRO, Marcia Carla Pereira. Curso avançado de direito comercial. 10ed. São Paulo: Revista dos Tribunais, 2016.

LUIZE, Marcelo Shima. Cláusulas de indenização e resolução contratual em operações de fusão e aquisição: necessidade ou mera reprodução do modelo anglosaxão? In. KLEINDIENST, Ana Cristina (Coord). Estudos aplicados de direito empresarial societário. São Paulo: Almedina, 2016. Disponível em: <http://www.veirano.com.br/upload/content_attachments/456/2016_Estudos_aplicad os_direito_Cap_Clausulas_indenizacao_resolucao_original.pdf > Acesso em 3 de setembro de 2018.

POSNER, Richard A. A economia da justiça. Tradução de Evandro Ferreira e Silva. 1ed. São Paulo: WMF Martins Fontes, 2010.

RAMOS, Ana Rita Picolli Gomes de O. et al. Fusões, aquisições, reorganizações societárias e due diligence. São Paulo: Saraiva, 2012.

RAUPP, Fabiano Maury; WARKEN, Ricardo Muller. Utilização da due diligence em processos de fusão e aquisição. Pensar Contábil, Rio de Janeiro, v. 11, n. 45, p. 34-40, jul/set. 2009. Disponível em: < http://www.atena.org.br/revista/ojs-2.2.308/index.php/pensarcontabil/article/view/4 > Acesso em 19 de agosto de 2018.

SALAMA, Bruno Meyerhof. Direito, Justiça e Eficiência: A perspectiva de Richard Posner. Fundação Getúlio Vargas, 2008. Disponível em: < https://works.bepress.com/bruno_meyerhof_salama/30/ > Acesso em 19 de agosto de 2018.

TEIXEIRA, Tarcísio. Compromisso e promessa de compra e venda: distinções e novas aplicações dos contratos preliminares. 2ed. São Paulo: Saraiva, 2015. 